
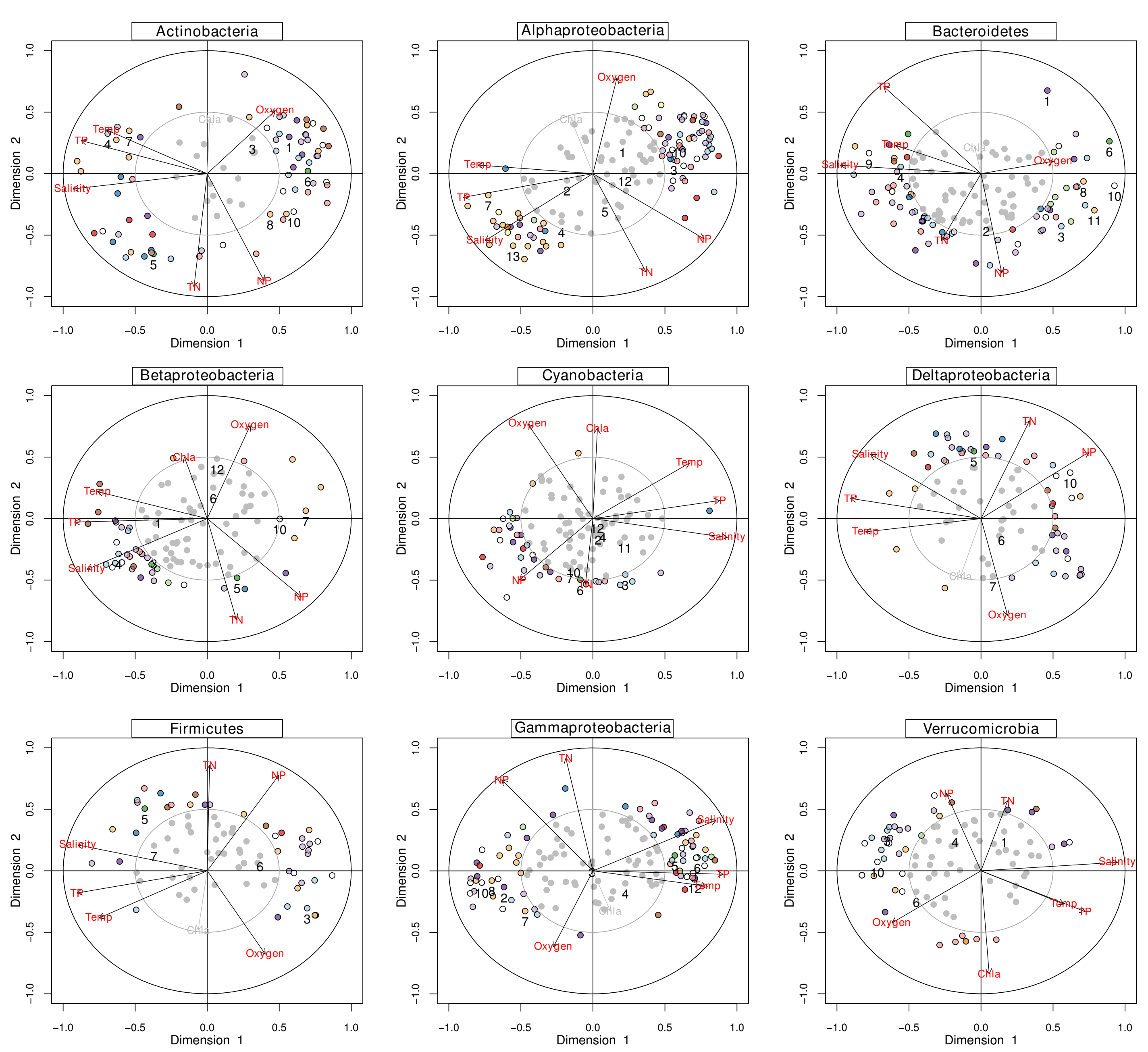

KEGG Metabolic Category

Central carbohydrate metabolism - Fatty acid metabolism

o Lipid metabolism

- Terpenoid biosynthesis

- Polyamine

- Nucleotide metabolism

- Transport

- Two-component regulatory system

- Amino acid metabolism

- Cofactor and vitamin biosynthesis

- Carbon fixation

- Methane metabolism

Other

\section{KEGG Module}

$1=$ Ubiquinone biosynthesis $2=$ Menaquinone biosynthesis 0 $3=$ Glycolysis (EMP) 0

$4=$ Glycolysis (ED)

$5=$ Isoprenoid biosynthesis (Mev)

$6=$ Isoprenoid biosynthesis (Non-Mev) 0

$7=\mathrm{Fe}^{3+}$ transport 0

$8=$ Fe-complex transport

$9=\mathrm{NQR}$ dehydrogenase $\left(\mathrm{Na}^{+}\right)$

$10=\mathrm{NDH}$ dehydrogenase $\left(\mathrm{H}^{+}\right)$

$11=$ Competence related transporter

$12=$ Glutathione biosynthesis

$13=$ Glycine betaine transport 0 